\title{
Yungahelea, a new genus of predaceous midge from northwestern Argentina (Culicomorpha: Ceratopogonidae)
}

\author{
GUSTAVO R. SPINELLI ${ }^{1,2}$, MARÍA M. RONDEROS ${ }^{1,3}$, MARIANO DONATO ${ }^{2}$ and AUGUSTO SIRI ${ }^{2}$ \\ ${ }^{1}$ División Entomología, Museo de La Plata, Paseo del Bosque s/n, 1900 La Plata, Argentina \\ ${ }^{2}$ Instituto de Limnología "Dr. Raúl A. Ringuelet”, Consejo Nacional de Investigaciones Científicas y Técnicas de la \\ Argentina, Universidad Nacional de La Plata, Boulevard 120 y 62 s/n, 1900 La Plata, Buenos Aires, Argentina \\ ${ }^{3}$ Centro de Estudios Parasitológicos y de Vectores, Consejo Nacional de Investigaciones Científicas y Técnicas de la \\ Argentina, Universidad Nacional de La Plata, Boulevard 120 y 62 s/n, 1900 La Plata, Buenos Aires, Argentina
}

Manuscript received on February 2, 2017; accepted for publication on March 8, 2017

\begin{abstract}
A new monotypic genus and species of predaceous midge from the southernmost area of the Argentinean Yungas, Yungahelea australis Spinelli and Ronderos, is described and illustrated from male and female adults. It belongs to a group containing the Ceratopogonini genera Parabezzia Malloch, Diaphanobezzia Ingram and Macfie, Spinellihelea Borkent, Grogan and Picado, Leptohelea Wirth and Blanton, and Fittkauhelea Wirth and Blanton. Phylogenetic interpretation indicates that Yungahelea is the sister group of Spinellihelea or the clade composed by Parabezzia and Diaphanobezzia.
\end{abstract}

Key words: Diptera, Ceratopogonidae, Yungas, new genus, phylogeny.

\section{INTRODUCTION}

A recent survey of ceratopogonids in the Yungas of the Tucumán province in northwestern Argentina revealed the presence of males and females of a species which could not be placed within any of the hitherto recognized genera in the family. The species clearly belonged to a small group of genera of Ceratopogonini representaed by Parabezzia Malloch, Spinellihelea Borkent, Grogan and Picado, Diaphanobezzia Ingram and Macfie, Fittkauhelea Wirth and Blanton, and Leptohelea Wirth and Blanton. This group of genera, mostly distributed in the Neotropical region, was reviewed by Borkent et

Correspondence to: Gustavo Ricardo Spinelli

E-mail: spinelli@fcnym.unlp.edu.ar al. (2008) on the basis of morphological characters, being this publication the only antecedent in the literature dealing with its phylogeny.

The purpose of this paper is to describe the new genus and species and to interpret its cladistic relationships to related genera.

The ZooBank Life Science Identifier (LSID) of this publication is: urn:1sid:zoobank. org:pub:5A EB 96EF-5A 33 - 4368 - B FE 6B8B4341198FE

\section{MATERIALS AND METHODS}

All specimens were slide mounted in Canada balsam and examined and measured with a binocular compound microscope. Photomicrographs were taken with a digital camera Micrometrics 
SE Premium, through a Nikon Eclipse E200 microscope and a Nikon SMZ 1000 stereoscopic magnifying. Terms of structures follow those used in the Manual of Central America Diptera (Brown et al. 2009).

In order to establish the phylogenetic relationships of the new genus Yungahelea, a cladistic analysis was performed using the character setting of Borkent et al. (2008) with some modifications that are shown below. Using more inclusive synapomophies as argument, the terminals chosen for this analysis were the genera Parabezzia, Spinellihelea, Diaphanobezzia, Fittkauhelea, and Leptohelea, those belonging to the Spinellihelea clade within the tribe Ceratopogonini of the cladogram made by Borkent et al. (2008). The resulting data matrix of 11 characters and 7 taxa is shown in Table I. The genus Bahiahelea Wirth was selected as outgroup since it is one of the two sister groups of the Spinellihelea clade in the phylogenetic analysis of Borkent et al. (2008) and belongs to the Neotropical region.

Data matrix was analyzed in the program TNT version 1.1 (Goloboff et al. 2008) applying implied weights as optimality criteria. A TNT script (propk. run) written by Salvador Arias was used to calculate the appropriate value for constant $\mathrm{k}$. After running the script, a value of $\mathrm{k}=3$ was obtained for our data set and was selected for data analysis. To obtain the most parsimonious cladogram, an exact solution was applied. Character support was estimated with absolute and relative Bremer support values.
The specimens examined, that include species of all analyzed genera except Leptohelea, are deposited in the collection of the Museo de La Plata, Argentina (MLPA). For diagnoses of the involved genera see Wirth and Blanton (1970), Grogan and Wirth (1977), Wirth and Grogan (1988), Wirth (1992) and Borkent et al. (2008), and characters on the male wing and male genitalia of Leptohelea may be found in Borkent and Spinelli (2007).

\section{CHARACTERS AND CHARACTER STATES}

0. Maxillary palpus: (0) 5-segmented; (1) 4-segmented; (2) 3-segmented.

1. Eyes: (0) bare; (1) pubescent.

2. Female claws: (0) with basal inner tooth; (1) without basal inner tooth.

3. Female wing length/width: (0) higher than 2.45; (1) "rounded" (about 2.00).

4. Female wing costal extension: (0) long; (1) very reduced or absent.

5. Wing microtrichia: (0) absent; (1) present.

6. Anterior margin of male wing: (0) bent where $\mathrm{R}_{3}$ ends; (1) straight where $\mathrm{R}_{3}$ ends.

7. Male forecoxal setae: (0) normally developed; (1) markedly developed, stout.

8. Male tibiae: (0) with normally developed setae; (1) very spinose, especially in the hind tibia.

9. Male wing costa: (0) not extending beyond apex of radial cell; (1) extending beyond apex of radial cell.

TABLE I

Data matrix for 7 taxa and 11 morphological characters used in the cladistic analysis.

\begin{tabular}{lccccccccccc}
\hline & $\mathbf{0}$ & $\mathbf{1}$ & $\mathbf{2}$ & $\mathbf{3}$ & $\mathbf{4}$ & $\mathbf{5}$ & $\mathbf{6}$ & $\mathbf{7}$ & $\mathbf{8}$ & $\mathbf{9}$ & $\mathbf{1 0}$ \\
\hline Bahiahelea & 0 & 0 & 0 & 0 & 0 & 1 & 1 & 0 & 0 & 1 & 0 \\
Leptohelea & 2 & 0 & 1 & 1 & 0 & 1 & $?$ & $?$ & $?$ & 1 & 1 \\
Fittkauhelea & 1 & 1 & 0 & 1 & 0 & 0 & 1 & 0 & 0 & 0 & 2 \\
Spinellihelea & 1 & 0 & 1 & 0 & 1 & 1 & 0 & 0 & 0 & 0 & 2 \\
Diaphanobezzia & 1 & 1 & 0 & 0 & 1 & {$[01]$} & {$[01]$} & 1 & {$[01]$} & 0 & 3 \\
Parabezzia & 1 & 0 & 1 & 0 & {$[01]$} & 1 & 1 & 1 & 0 & 0 & 3 \\
Yungahelea & 1 & 0 & 0 & 0 & 1 & 1 & 0 & 0 & 1 & 0 & 3 \\
\hline
\end{tabular}


10. Male parameres: (0) fused into large sphare; (1) separated, elongated, slender; (2) absent or very reduced; (3) fused forming a flat medial structure.

\section{RESULTS}

Yungahelea SPINELLI AND RONDEROS, NEW GENUS (FIGURES 1-23)

ZooBank Life Science Identifier (LSID) urn:1sid:zoobank.org:act:B0302638-5BBE-45D292FB-D651E47A5322

Type species. Yungahelea australis Spinelli and Ronderos, new species.

Diagnosis. Male: the only genus of Ceratopogonidae with the following combination of features: eyes bare, widely separated, palpal segments 4 and 5 fused and long as segment 3, wing with bunch of 9-11 stout, appressed setae proximad to basal arculus, anterior margin bent where $\mathrm{R}_{3}$ ends, with one radial cell and $\mathrm{M}_{2}$ forking distal to $\mathrm{r}-\mathrm{m}$, halter with narrow stem and bulbous knob, coxae without long stout setae, tibiae very spinose, hind leg first tarsomere with strong basal spine and single row of ventral palisade setae, tergite 9 with a posteromedial notch, parameres fused medially, well developed. Female: the only genus of Ceratopogonidae with the following combination of features: eyes bare, widely separated, palpal segments 4 and 5 fused and long as segment 3 , clypeus fused with ventromedial margin of eye, wing with one large radial cell, costal extension relatively short and $\mathrm{M}$ forking distal to $\mathrm{r}-\mathrm{m}$, halter with narrow stem and bulbous knob, legs lacking armature, sternite 9 separate medially.

Male (Fig. 1). Head (Fig. 3): eyes separated dorsomedially by distance equal to diameter of about 5 ommatidia, bare of interommatidial macrotrichia. With single vertex seta. Antenna (Fig. 4) with sparse plume of decumbent setae, 13 separate flagellomeres, flagellomeres 11-13 more elongate than flagellomeres 2-10, flagellomere
1 without sensilla coeloconica. Mouthparts moderately short. Mandible, lacinia not visible. Palpus (Fig. 3) with 4 segments (segments 4 and 5 fused), very slender, segment 3 with few capitate sensilla scattered on mesal surface. Thorax (Fig. 5) with three anterior pronotal apodemes. Scutum with elongate setae. Scutellum rounded in dorsal view. Legs (Fig. 6) with fore- and midfemora, tibiae slender. Forecoxa with normally developed setae similar to those found on mid- and hind coxa. Femora with pair of subapical spines. Forefemur lacking ventral spines. Hind femur, tibia swollen.
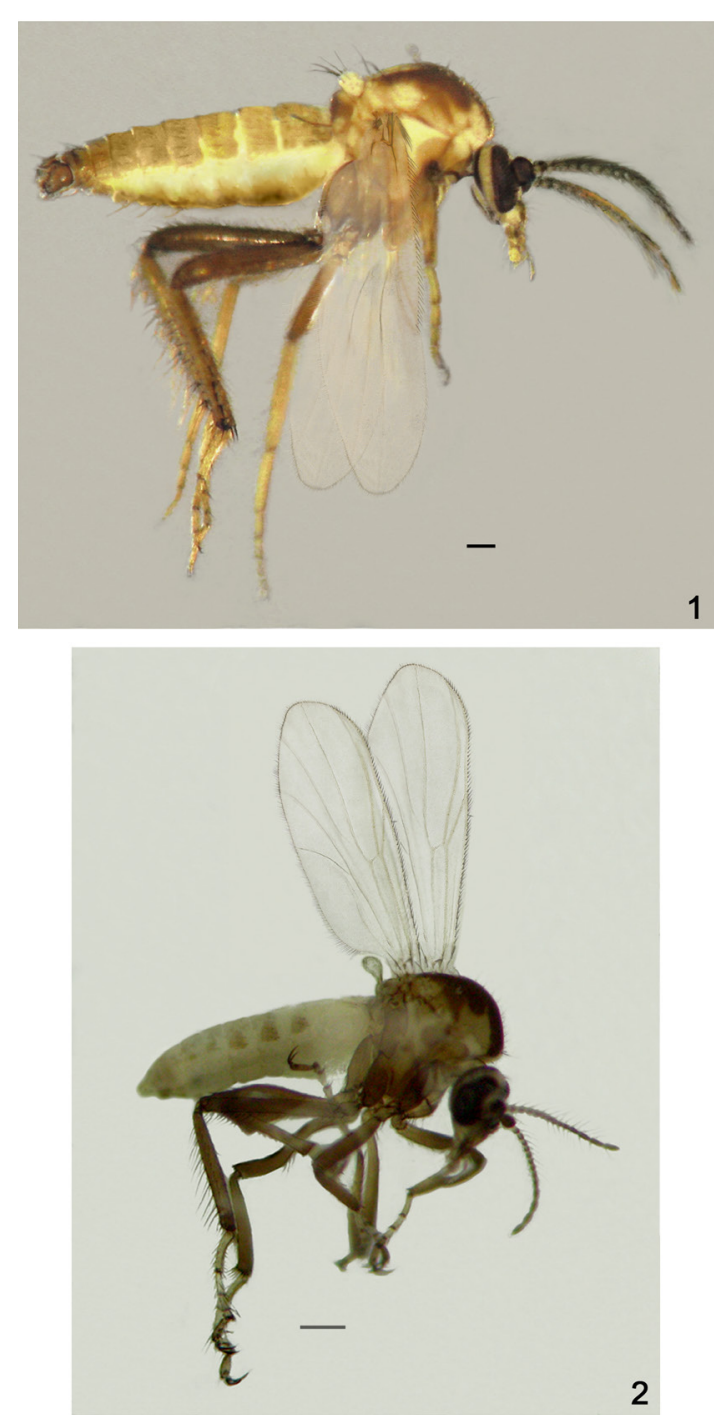

Figures 1-2. Yungahelea australis. (1) male; (2) female. 

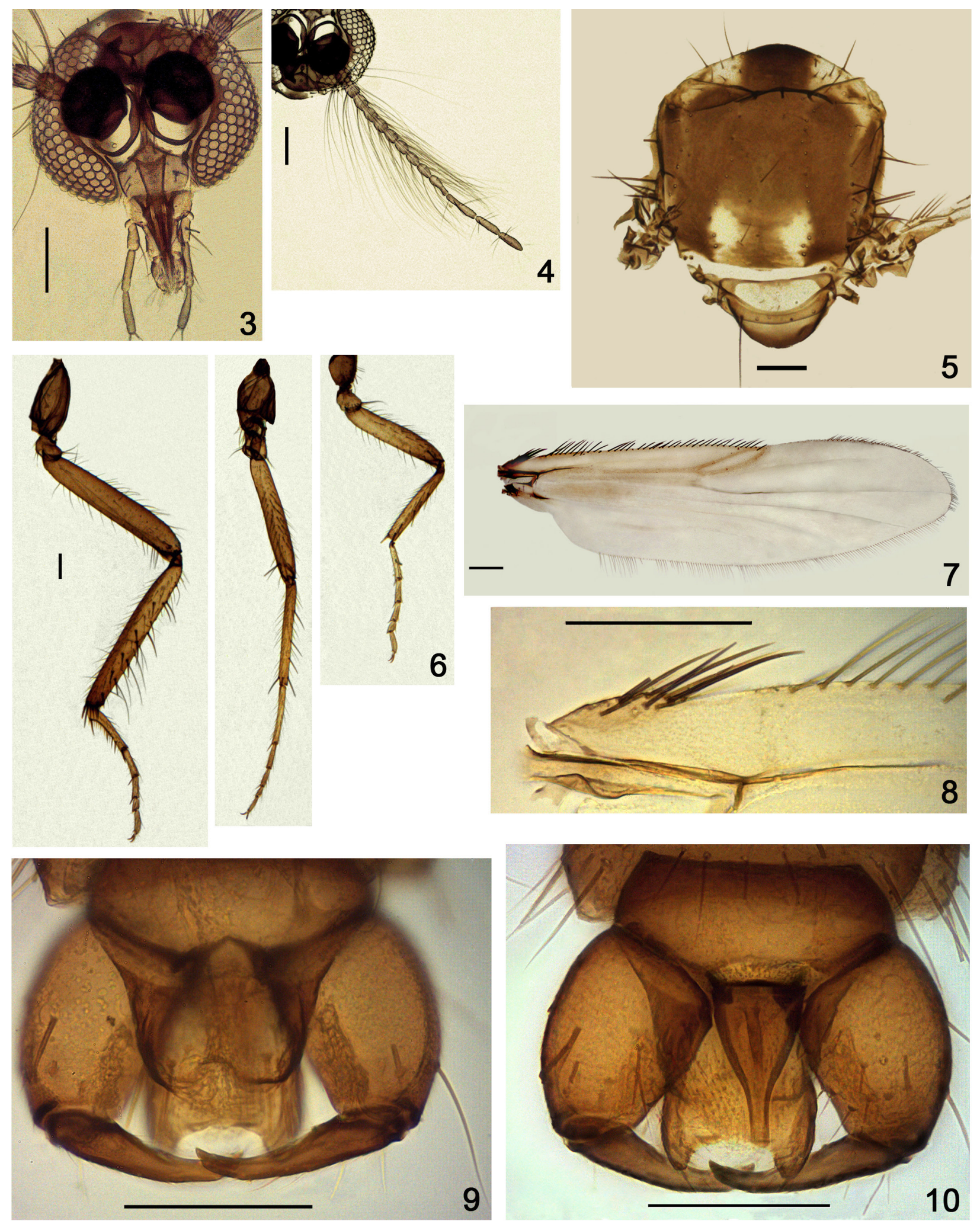

Figures 3-10. Yungahelea australis, male. (3) head; (4) antenna; (5), thorax, dorsal view; (6) (left to right) hind, mid, fore legs; (7) wing; (8) detail of bunch of setae on costa proximad to basal arculus; (9) genitalia, dorsal view; (10) genitalia, ventral view. 

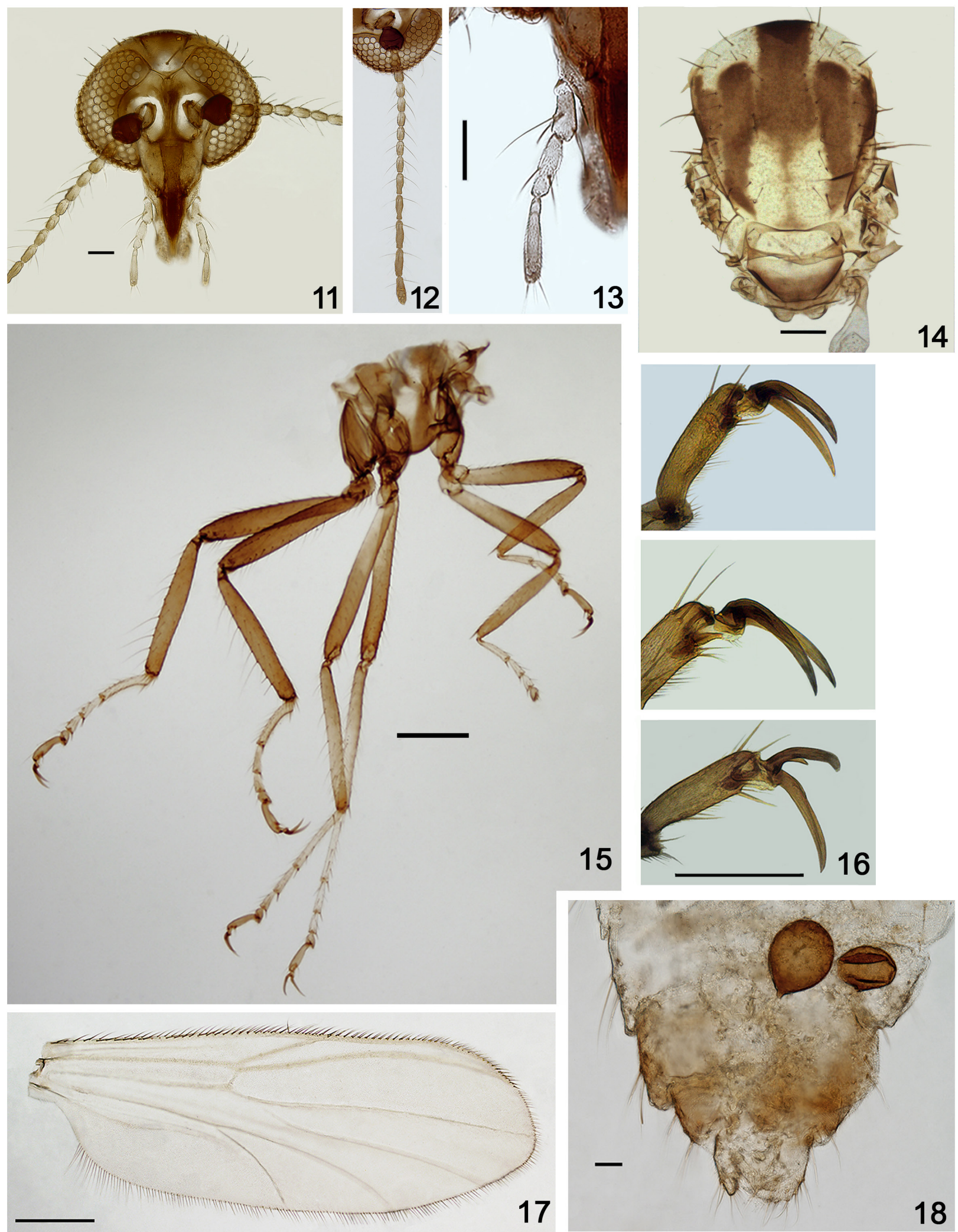

15
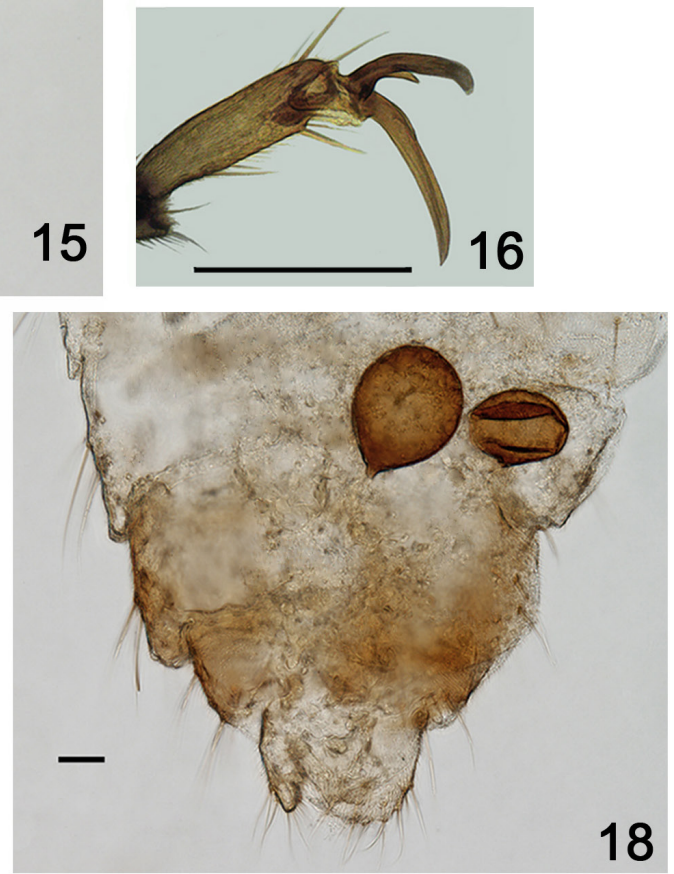

Figures 11-18. Yungahelea australis, female. (11) head; (12) antenna; (13) palpus; (14), thorax, dorsal view; (15) legs; (16) (top to bottom) tarsal claws of fore, mid, hind legs; (17) wing; (18) tip of abdomen, showing spermathecae. 
Tibiae (Figs. 19-21) very spinose. Hind tibia apex with two rows of spines. Tarsomeres 1-3 with pair of apical spines, stronger on hind leg. Hind leg first tarsomere with strong basal spine and single row of ventral palisade setae, distal setae of palisade stronger than proximal setae. Fourth tarsomere of fore-, hind leg cordiform, subcylindrical on midleg. Claws on fore-, mid-, hind leg equal in size, equal on each leg, apically bifid. Empodium absent. Wing (Fig. 7) without macrotrichia, fine microtrichia present on surface. Anterior margin bent where $\mathrm{R}_{3}$ ends. Costa not extending beyond apex of $R_{3}$. Bunch of 9-11 stout, appressed setae proximad to basal arculus, separate from costal fringe by short distance (Fig. 8). Costal fringe well developed. Single radial cell shorter than in female, $\mathrm{r}-\mathrm{m}$ nearly perpendicular to $\mathrm{R}_{1}$. M bifurcating distal to $\mathrm{r}-\mathrm{m}$, with base of $\mathrm{M}_{2}$ well defined. Halter with narrow stem and swollen apex. Genitalia (Figs. 9-10): tergite 9 notched posteromesally, without apicolateral processes; cercus large, laterally compressed, directed posteriorly beyond margin of tergite 9 . Sternite 9 with posterior margin slightly concave. Gonocoxite short, $1.4 \mathrm{X}$ longer than greatest width, gonostylus elongate, as long as gonocoxite, with apex toothlike. Parameres (Fig. 22) fused medially, mesal process slender, lightly sclerotized, well developed, tip rounded. Aedeagus (Fig. 23) elongate, triangular, rounded apically.

Female (Fig. 2). As for male, except as follows. Head (Fig. 11): antenna (Fig. 12) with flagellomeres 1, 9-13 more elongate than flagellomeres 2-8. Clypeus fused with ventromedial margin of eye. Mouthparts moderately elongate. Mandible with 7 large teeth. Laciniae slender, with only apical spines. Palpus (Fig. 13) with 4 segments (segments 4 and 5 fused), 4+5 slightly longer than segment 3. Thorax (Fig. 14) brown, with pattern of pale areas. Legs (Fig. 15) lacking armature. Hind tibial comb with 8 spines. Claws on fore-, mid-, hind leg elongate, equal or nearly equal in size, equal on each leg, each claw with small basal inner tooth (Fig. 16). Wing (Fig. 17) with costa extending beyond apex of $\mathrm{R}_{3}$ by short distance, without bunch of stout setae proximad to basal arculus. Abdomen (Fig. 2) with two spermathecae (Fig. 18). Sternite 9 separate medially. Segment 10 with subbasal pair of short setae, subapical pair of elongate setae. Cercus moderately elongate.

Taxonomic discussion. Yungahelea belongs to a group containing the following four Ceratopogonini genera: Parabezzia, Diaphanobezzia, Spinellihelea, and Fittkauhelea. In these genera the palpus is reduced to four segments due to a fusion of segments 4 and 5, the costa does not extend beyond the apex of the radial cell in the male wing and the male parameres are absent or very reduced, or they are fused forming a flat medial structure. Due to its well developed parameres, Yungahelea is apparently most similar to Parabezzia and Diaphanobezzia, but in these genera the male forecoxa bear several stout and markedly developed setae; Diaphanobezzia also differs from this new genus by the peculiar sac-like halter. Due the presence of normally developed setae in the male forecoxa and the anterior margin of the male wing bent where $\mathrm{R}_{3}$ ends, Yungahelea is very similar to the recently described genus Spinellihelea from Costa Rica, but in the latter the female claws lack basal inner tooth and the male tibiae, especially the hind one are slender and bear normally developed setae.

Etymology. The name Yungahelea, gender feminine, is related to the Yunga ecoregion where the specimens here described were collected.

Yungahelea australis SPINELLI AND RONDEROS, NEW SPECIES

ZooBank Life Science Identifier (LSID) urn:1sid:zoobank.org:act:50264358-E8DC-4C2598B0-F4B7E441ACE1

Diagnosis. Male and female as for genus. 


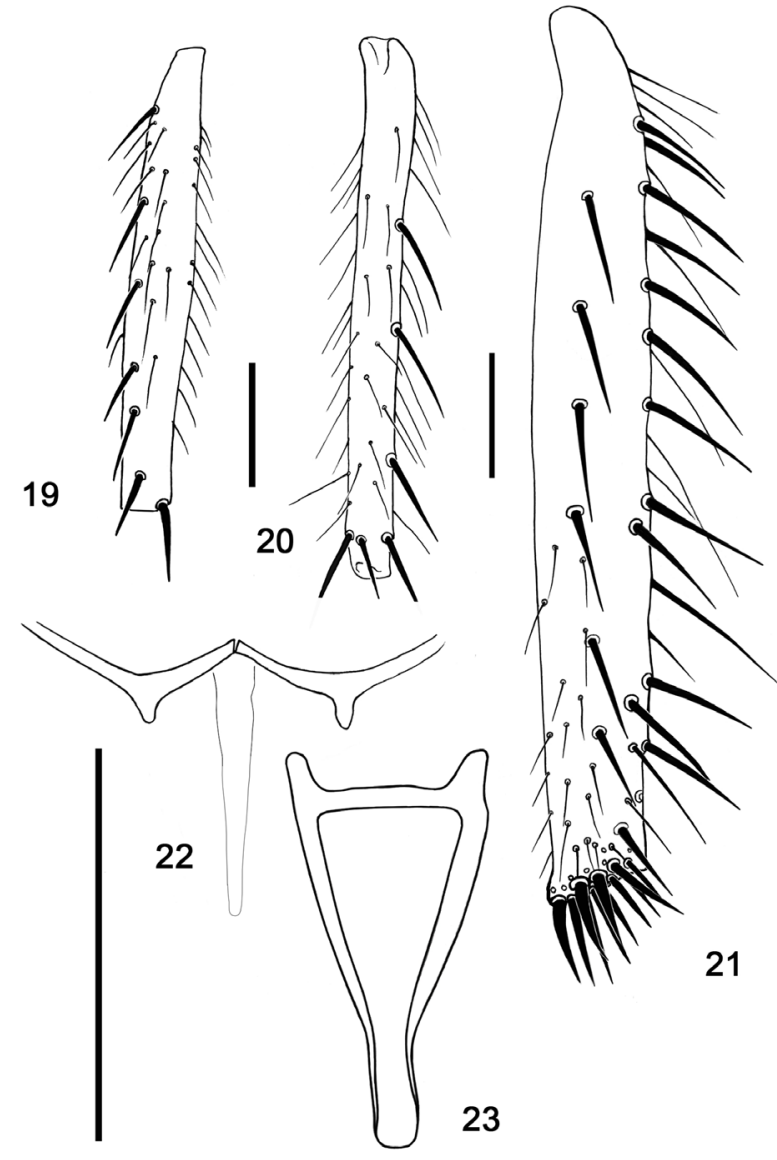

Figures 19-23. Yungahelea australis, male. (19) foretibia; (20) midtibia; (21) hind tibia; (22) parameres; (23) aedeagus.

Male (Fig. 1). Head (Fig. 3) brown, except palpus pale brown. Thorax (Fig. 5) brown. Scutum with humeral areas and prealar areas pale, prescutellar depression with two small, admedian pale areas. Scutellum pale brown. Wing (Fig. 7) membrane infuscated, slightly more so anterior of $\mathrm{M}$, wing length 1.17-1.22 $(1.20, \mathrm{n}=3) \mathrm{mm}$, costal ratio 0.52$0.55(0.53, \mathrm{n}=3)$, costa setae arising all along from anterior margin of costa. Halter pale. Legs (Fig. 6): forecoxa with 10-12 normally developed setae, mid- and hind coxa with 10-12 and 2-3 similar setae, respectively. Femora hairy and with pair of subapical spines. Fore- and midtibia with 3-5 dorsal spines (Figs. 19, 20). Midtibia without spur, with 3 apical spines (Fig. 20). Hind tibia with 15-18 dorsal and mesal strong spines (Fig. 21). Abdomen
(Fig. 1) brown, pleura yellowishy. Genitalia (Figs. 9-10): tergite 9 extending to level of $3 / 4$ gonocoxite length, apex notched mesally; sternite $92.5 \mathrm{X}$ wider than long, posterior margin slightly concave. Gonocoxite1.4X longer than greatest width, its anteromesal angle heavily sclerotized; gonostylus as long as gonocoxite, somewhat curved, tapering to slightly curved, toothlike, pointed tip. Parameres (Fig. 22) well developed; basal apodemes fused medially, each one slender, heavily sclerotized, directed anteromesally, with small, pointed, sublateral process directed posteriorly; mesal process slender, lightly sclerotized, extending to level of 2/3 of gonocoxite length, tip rounded. Aedeagus (Fig. 23) triangular, 1.8X longer than its greatest width; basal, lateral arm heavily sclerotized; basal arch very low, extending 0.05 of total aedeagus length, distal portion relatively stout, 1/3 of total aedeagus length, surface smooth; apex lightly sclerotized, rounded.

Female (Fig. 2). Head (Fig. 11): antennal ratio 1.02$1.04(1.03, n=2)$. Clypeus with 10 slender, elongate setae. Mandible with 7 large, coarse teeth on inner margin, a few, tiny, slender teeth on outer margin. Thorax (Fig. 14) brown, humeral areas, admedian areas on prescutellar depression and prealar area extensively pale. Scutellum with 4 strong setae and 6 thinner ones. Wing (Fig. 17): uniformly slightly infuscated, length 1.26-1.28 (1.27, $\mathrm{n}=2) \mathrm{mm}$, costal ratio 0.94-0.96 $(0.95, \mathrm{n}=2)$, costal setae arising all anterior margin of costa. Abdomen (Fig. 2) whitish, tergites 3-7 with lateral brown, small spots. Spermathecae (Fig. 18) unequal in length, ovoid with short necks, smaller collapsed in the available specimens, larger measuring 76 by $60 \mathrm{um}$.

Immature stages. Unknown.

Distribution. Yungahelea australis is known only from the type locality. Specimens were collected using sweep nets at $656 \mathrm{~m}$ of altitude, in one of the 
a
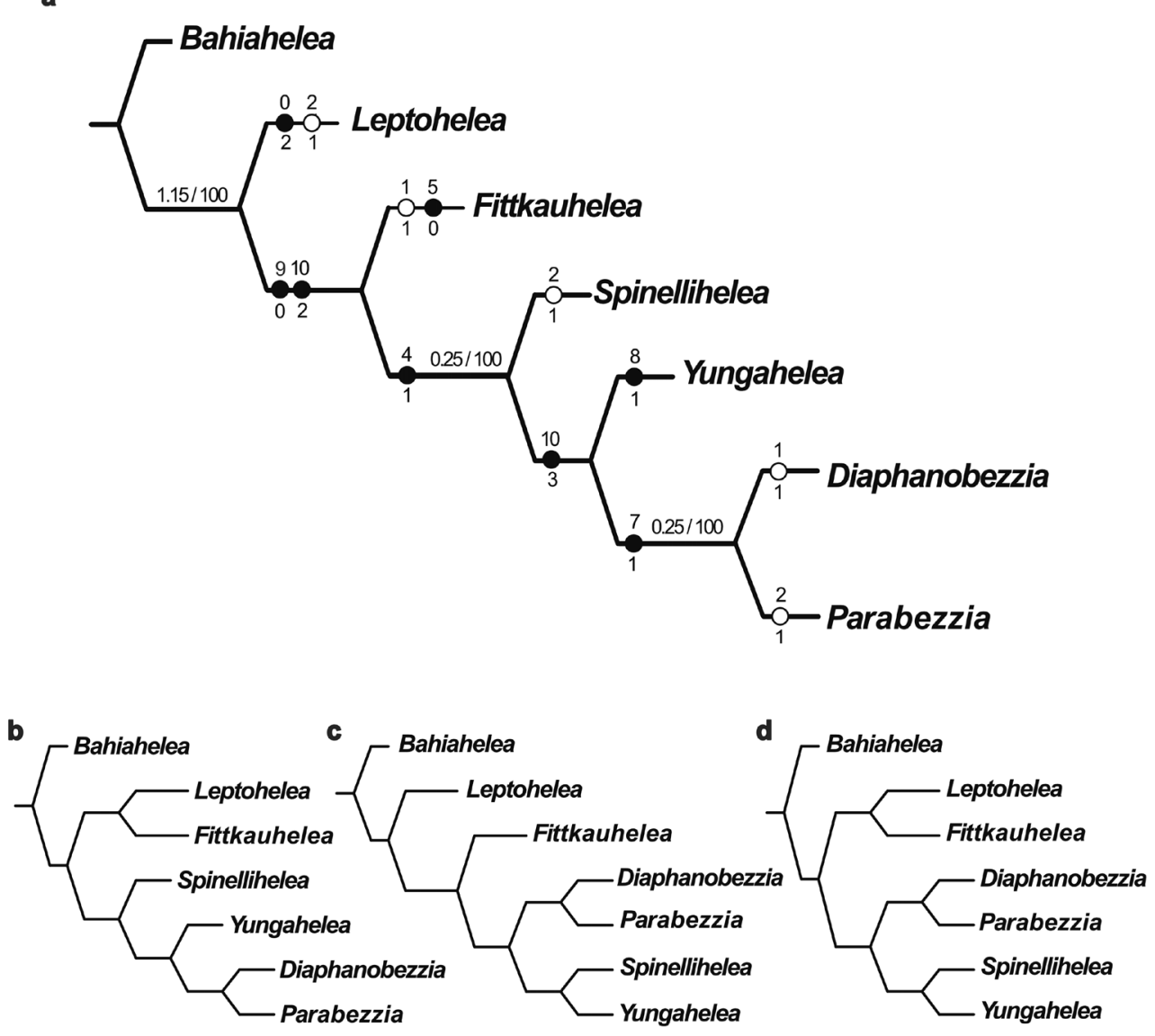

Figure 24. (a-d) cladograms obtained under $K=3$. The numbers above the nodes in cladogram a represent the absolute and relative Bremer supports, respectively.

southernmost patches of the Yungas cloud forest in South America.

Material examined. Holotype male on microscope slide, labeled "Yungahelea australis Spinelli and Ronderos," "Argentina, Tucumán, Departamento J. B. Alberdi, Escaba arriba, río Chavarría, -27,63988199, -65,79275743, 656 m, 10-XI-2014, M. Donato - A. Siri, sweep net" (MLPA). Allotype female and 3 paratypes ( 2 males, 1 female): same data as holotype.

Derivation of specific epithet. The specific name, australis, Latin for "southern", refers to the typelocality in the southernmost area of the Yungas.

\section{CLADISTIC ANALYSIS}

After the cladistic analysis four cladograms were obtained (Fit $=6.85, \mathrm{CI}=0.73, \mathrm{RI}=0.5)$ and are shown in Figure 24. The cladogram elected as reference (Fig. 24a) and cladogram in Figure 24b show Yungahelea $\mathrm{n}$. gen. as the sister group of the clade (Parabezzia, Diaphanobezzia) supported by the synapomorphy male parameres fused forming a flat medial structure [10 (3)]. The other two cladrograms (Figs. 24c and 24d) show Yungahelea as the sister group of Spinellihelea supported by the synapomorphy anterior margin of male wing bent where $\mathrm{R}_{3}$ ends [6 (0)]. All the cladograms have in common the clade (Diaphanobezzia, Parabezzia, 
Spinellihelea, Yungahelea) supported by the synapomorphy female wing with costal extension very reduced or absent [4 (1)]. Cladograms 24a and 24c show Fitkkauhelea as the sister group of the later clade, sharing the 4-segmented maxillary palpus [0 (1)].

\section{DISCUSSION}

The most recent phylogenetic analysis of the Ceratopogonini was performed by Borkent et al. (2008), where the clade of interest in this study showed a basal trichotomy formed by the clades (Parabezzia, Diaphanobezzia), (Fittkauhelea, Spinellihelea), and the genus Leptohelea. The first clade supported by the synapomorphy male forecoxa with markedly developed, stout setae, and the second one supported by the synapomorphy male parameres fused forming a flat medial structure. In our study, the inclusion of the new genus Yungahelea modified the phylogenetic relationships performed by Borkent et al. (2008), since that genus became the sister group of Spinellihelea and placed Fittkauhelea in a more basal position. The clade (Parabezzia, Diaphanobezzia) remains supported by the same synapomorphy [7 (1)], while Yungahelea is also distinguished from this clade by the very spinose male hind tibia [8 (1)]. The clade (Diaphanobezzia, Parabezzia, Spinellihelea, Yungahelea) was present in all of our cladograms, sharing the synapomoprhy female wing with costal extension very reduced or absent [4 (1)].

From the cladograms found in our analysis, two main groups could be distinguished, cladograms $24 \mathrm{a}$ and 24b showing Yungahelea as the sister group of (Parabezzia, Diaphanobezzia), and cladogram 24c and 24d showing Yungahelea as the sister group of Spinellihelea. As was mentioned above, the former relationship is supported by the character male parameres fused forming a flat medial structure [10 (3)]. It is important to point out that the character state male parameres very reduced or absent [10
(2)] is shared by Spinellihelea and Fittkauhelea and represents a synapomorphy in the cladogram elected as reference, but was not enough to put together those genera. Instead, the inclusion of the new genus in the Ceratopogonini changed the character interpretation. The new combination of characters plus the finding of a new synapomorphy that is the anterior margin of male wing bent where $\mathrm{R}_{3}$ ends [6 (0)], forced the displacement of the genus Fittkauhelea to a basal position becoming therefore more closely related to Leptohelea.

Finally, the new genus exhibits a bunch of 9-11 stout, appressed setae proximad to basal arculus which are separated from the costal fringe by a short distance, and the apex of tergite 9 notched mesally, being these two characters autapomorphies that reinforces the erection of Yungahelea as a new genus.

\section{ACKNOWLEDGMENTS}

We are very grateful to PIP 0568-CONICET for economic support during this investigation and to Nélida Caligaris for technical assistance in the laboratory. Our gratitude also to Mónica Caviglia for the English proofreading, and to Patrycja Dominiak for the appropriate suggestions on the manuscript acting as a journal reviewer.

\section{REFERENCES}

BORKENT A, GROGAN WL AND PICADO A. 2008. A new genus of predaceous midge (Diptera: Ceratopogonidae) from Costa Rica. Proc Entomol Soc Washington 110: 622634.

BORKENT A AND SPINELLI GR. 2007. Catalog of the new world biting midges South of the United States of America (Diptera: Ceratopogonidae). Contrib Entomol Int 4(1): 1-107.

BROWN BV, BORKENT A, CUMMING JM, WOOD DM, WOODLEY NE AND ZUMBADO MA. 2009. Manual of Central American Diptera. Vol. 1. NRC Research Press, Ottawa, Ontario, Canada, 714 p.

GOLOBOFF PA, FARRIS JS AND NIXON KC. 2008. TNT, a free program for phylogenetic analysis. Cladistics 24 : $1-13$. 
GROGAN WL AND WIRTH WW. 1977. A revision of the Nearctic species of Parabezzia Malloch (Diptera: Ceratopogonidae). J Kansas Entomol Soc 50: 49-83.

WIRTH WW. 1992. A new genus of Ceratopogonini (Diptera: Ceratopogonidae) from Brazil. Proc Entomol Soc Washington 94: 276-281.
WIRTH WW AND BLANTON FS. 1970. New genera of Neotropical Ceratopogonidae (Diptera). Fla Entomol 53: 7-14.

WIRTH WW AND GROGAN WL. 1988. The predaceous midges of the world (Diptera: Ceratopogonidae; Tribe Ceratopogonini). Flora and Fauna Handbook 4. E.J. Brill, Leiden: $x v+1260$ p. 